\title{
SIMULASI NUMERIK ALIRAN MELEWATI NOZZLE PADA EJECTOR FRESH WATER GENERTOR DENGAN VARIASI DIAMETER EXIT NOZZLE DAN TEKANAN PRIMARY FLOW KONSTAN DI LABORATORIUM REAL ENGINE
}

\author{
WA Putranto*, Khaeroman \\ Jurusan Teknika, Politeknik Maritim Negeri Indonesia \\ Jl. Pawiyatan Luhur I/ 1 Bendan Duwur, Semarang 50233. \\ *Email: wahyu_ap@polimarin.ac.id
}

\begin{abstract}
Abstrak
Fresh water generator ( $F W G)$ merupakan salah satu alat di kapal yang digunakan untuk merubah air laut menjadi air tawar. Ejektor adalah salah satu komponen penting pada $F W G$. Kinerja ejektor berpengaruh terhadap jumlah produksi air tawar yang dihasilkan. Ejektor berfungsi untuk memvakumkan ruangan pada evaporator serta menghilangkan brine/ air garam (air dengan salinitas tinggi) dari bagian bawah ruangan evaporator. Secara umum ejektor merupakan pompa statis yang bekerja berdasarkan dengan prinsip kevakuman. Kevakuman yang terjadi pada ejektor sangat mempengaruhi performa dan kemampuan hisap sisi secondary flow (suction area). Tujuan penelitian ini adalah mengetahui pengaruh variasi diameter exit nozzle pada ejektor terhadap tekanan dan kecepatan di secondary flow (suction area) yaitu pada sisi isapan udara (vakum). Penelitian ini dilakukan secara simulasi numerik menggunakan software komersial CFD untuk memprediksi fenomena aliran fluida yang melewati nozel pada ejektor dengan memvariasikan diameter exit nozzle meliputi 5, 6, dan $7 \mathrm{~mm}$. Tekanan masuk (primary flow) pada nozel adalah $400 \mathrm{kPa}$ (4 bar). Jarak antara ujung exit nozzle dengan pipa aliran keluar dibuat dengan posisi tetap. Ujung exit nozzle berada pada posisi $3 \mathrm{~mm}$ masuk ke dalam pipa saluran keluar yang diukur dari posisi ujung bagian dalam. Hasil simulasi menunjukkan ejektor dengan diameter exit nozzle $7 \mathrm{~mm}$ menghasilkan tekanan terbesar yaitu 2,92 bar dan memberikan performansi yang optimum dengan menghasilkan tekanan di secondary flow (suction area) sebesar 0,81 bar sehingga menyebabkan tingkat kevakuman pada ruang evaporator semakin cepat. Semakin cepat ruang evaporator vakum maka semakin cepat pula dimulainya proses pembuatan air laut menjadi air tawar pada alat $F W G$
\end{abstract}

Kata kunci: diameter nozzle, ejektor FWG, laju aliran, primary flow.

\section{PENDAHULUAN}

Fresh water generator (FWG) adalah salah satu alat di kapal yang digunakan untuk merubah air laut menjadi air tawar (Iing dkk, 2019). Prosesnya adalah menguapkan air laut di dalam evaporator kemudian uap air laut tersebut didinginkan dengan cara kondensasi di dalam pesawat destilasi sehingga menghasilkan air tawar.

Adapun bagian-bagian FWG adalah evaporator, kondensor, demister, ejektor, pompa ejektor, dan pompa destillate. Penyebab menurunnya produksi air tawar pada FWG adalah menurunnya produksi air tawar pada FWG. Ejektor adalah salah satu bagian FWG yang berfungsi untuk memvakumkan ruangan (tempat evaporator dan kondensor) serta menghilangkan brine/ air garam (air dengan salinitas tinggi) dari bagian bawah ruangan (evaporator).

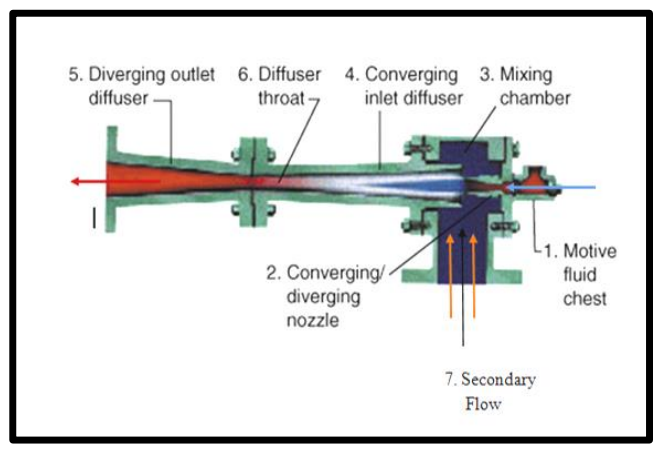

Gambar 1. Konstruksi dan komponen ejektor (James R Line.1997)

Komponen utama ejektor adalah nosel. Nosel merupakan bagian terkecil pada ejektor yang berfungsi untuk mengkonversi 
energi tekanan pada primary fluid menjadi energi kinetik. Pada bagian ini, fluida akan mengalami shock wave sebagai akibat dari perubahan tekanan dan kecepatan secara mendadak (Zhu dkk, 2013).

Ejektor dibuat untuk menciptakan ruang hampa yang hampir sempurna dengan kemampuan hisap yang kuat. Konstruksi ejektor dibuat dengan berbagai komponen untuk memaksimalkan kemampuannya. Konstruksi ejektor secara umum terdapat pada Gambar 1.

Ejektor sebagai pompa memiliki karakterisrik kemampuan hisap yang tinggi. Secara umum karakteristiknya dipengaruhi oleh geometri komponen yang terdiri terdiri dari tiga bagian utama yaitu: nozzle, ruang pencampur dan diffuser (Rizgar B. dkk. 2015)

Novi dan Syamsuri (2017) melakukan penelitian yang dilakukan secara simulasi numerik menggunakan software komersial CFD dengan $k$-epsilon untuk memprediksi fenomena aliran yang melewati nozzle pada ejector converging-diverging dengan memvariasikan diameter exit nozzle meliputi $3,5 \mathrm{~mm} ; 4 \mathrm{~mm} ; 5$ $\mathrm{mm}$; dan $5,5 \mathrm{~mm}$. Hasil simulasi menunjukkan steam ejector dengan diameter exit nozzle terkecil 3,5 mm memberikan performansi yang optimum karena memiliki kecepatan tertinggi, maka tingkat vakum pada mixing chamber meningkat menyebabkan massa secondary flow bertambah dan nilai entrainment ratio semakin tinggi.

Susanto dkk (2020) melakukan penelitian eksperimental pengaruh variasi bukaan katup bypass primary flow dan diameter throat nozzle terhadap entrainment ratio ejector. Parameter pada penelitian ini adalah variasi bukaan katup Bypass ada 5 posisi bukaan, pada primary flow mengalir fluida sebanyak 30 liter, diameter throat nozzle 2, 3 dan $5 \mathrm{~mm}$. Hasil eksperimen diperoleh bahwa laju aliran massa tertinggi terjadi pada nozzle 3 dengan dengan geometri ukuran diameter throat $5 \mathrm{~mm}$ dan diameter ujung nozzle $10 \mathrm{~mm}$. Laju aliran massa nozzle 3 pada primary flow $0.20689 \mathrm{Kg} / \mathrm{s}$. Laju aliran massa nozzle 3 pada secondary flow $0.01177 \mathrm{Kg} / \mathrm{s}$. Nilai entrainment ratio tertinggi nozzle 1 terjadi saat bukaan katup Bypass 3/4 dengan nilai 0.1393. Nilai entrainment ratio tertinggi nozzle 2 terjadi saat bukaan katup Bypass 1 atau tutup penuh dengan nilai 0.134 . Nilai entrainment ratio tertinggi nozzle 3 terjadi saat bukaan katup Bypass $3 / 4$ dengan nilai 0.0619 . Nilai entrainment ratio sangat dipengaruhi diameter Throat Nozzle dan kesesuain tekanan primary flow masuk ejector.

Ejektor pada FWG digunakan untuk membuat ruangan evaporator menjadi vakum secepatnya agar proses desalinasi segera terjadi. Maka perlu dilakukan penelitianpenelitian lebih lanjut untuk meningkatkan performa kinerja ejektor pada FWG. Salah satunya dengan cara memvariasikan ukuran diameter exit nozzel. Pada penelitian ini akan dilakukan penelitian pada ejektor FWG. Tekanan masuk (primary flow pada nozel yang dipilih adalah $400 \mathrm{kPa}$ (4 bar) kemudian variasi ukuran diameter exit nozzel adalah 5, 6, dan $7 \mathrm{~mm}$. Kemudian dilihat pengaruhnya terhadap laju aliran massa yang melewati exit nozzel dan penurunan tekanan pada evaporator.

\section{METODOLOGI}

Pada penelitian ini dilakukan dengan melakukan re-desain ejektor FWG di laboratorium real engine. Berikut adalah gambar ejektor FWG.

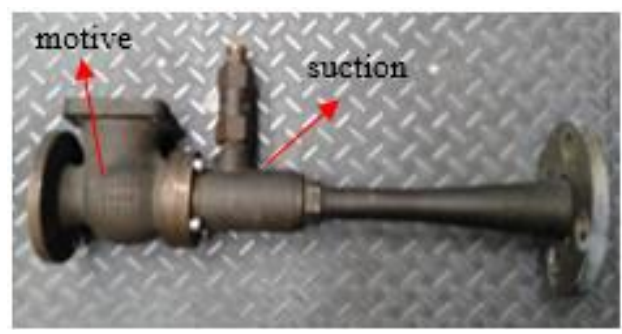

Gambar 2. Ejektor

Penelitian ini dilakukan dengan
metode numerik 2 dimensi yang menggunakan software CFD komersial. Model ejektor yang digunakan dalam simulasi ini adalah model ejektor (base model) berdasarkan ejektor aslinya. Adapun parameter pada penelitian ini tekanan masuk pada motive (primary flow) adalah konstan sebesar $400 \mathrm{kPa}$ (4 bar). Variasi diameter exit nozzle $(5$, 6, dan $7 \mathrm{~mm})$. Lama pengujian adalah 60 detik. 
Tahapan yang dilakukan pada penelitian ini dibagi menjadi tiga tahapan, yaitu:

\section{a. Pembuatan model ejektor}

Pada tahap ini ejektor FWG digambar sket pada kertas dan dilanjutkan dengan penggambaran menggunakan software solid Work. Ejektor kemudian dilakukan redesain geometrinya yaitu diameter exit nozzle dibuat dengan tiga variasi ukuran 5, 6 dan $7 \mathrm{~mm}$ ). Panjang throat $5 \mathrm{~mm}$. Jarak antara ujung nozzle dengan pipa aliran keluar dibuat dengan posisi tetap. Ujung nozzle berada pada posisi $3 \mathrm{~mm}$ masuk ke dalam pipa saluran keluar diukur dari posisi ujung bagian dalam. Gambar redesain ejektor terlihat pada gambar 3 .

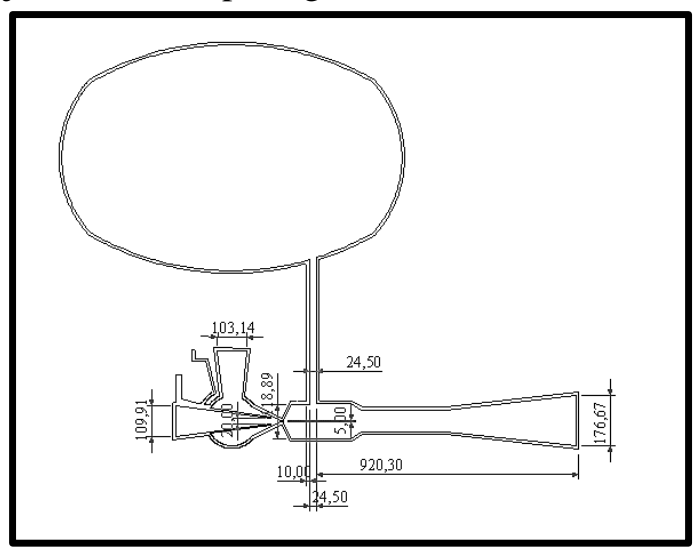

(a)

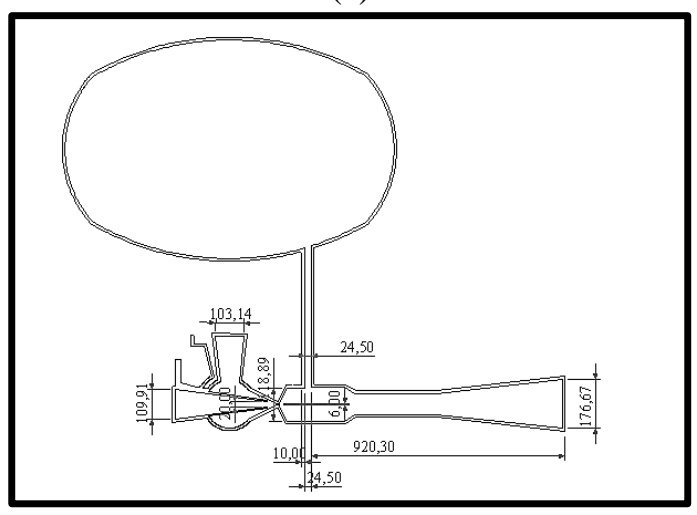

(b)

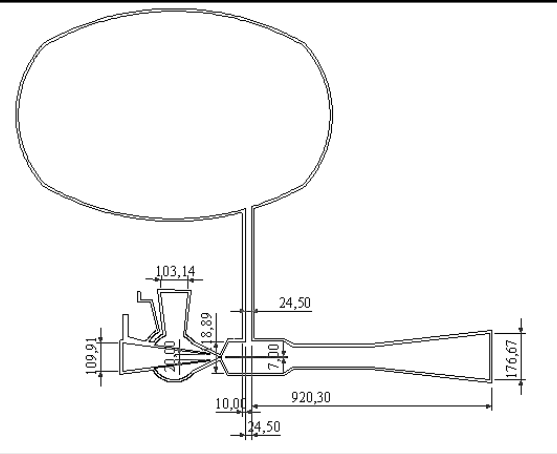

(c)

Gambar 3. Sketsa Ejector Diameter Nozzle (a) $5 \mathrm{~mm}$, (b) $6 \mathrm{~mm}$, (c) $7 \mathrm{~mm}$

b. Pengujian dengan software CFD

Pada tahap ini menggunakan software CFD komersial Fluent yang dimulai dengan memasukkan data hasil meshing. Laminar model pada penelitian ini menggunakan $k$ epsilon RNG dengan fuida yang dipakai adalah $\mathrm{H}_{2} \mathrm{O}$. Untuk properties density $(\rho)=$ $998,2 \mathrm{~kg} / \mathrm{m}^{2}$; viskosity $=0,001003 \mathrm{kgms}$, Kalor spesifik $=4182(\mathrm{~J} / \mathrm{kgK})$; Konduktivitas termal $(\mathrm{k})=0,6(\mathrm{~W} / \mathrm{m} \mathrm{K})$; dan Massa molekul $(\mathrm{Mm})=18,0152(\mathrm{~kg} / \mathrm{kmol})$.

Batasan yang terjadi pada aliran yang melewati benda uji berupa pressure inlet 4 bar dan pressure outlet 1 bar. Untuk Gauge Total Pressure: 0,986923 atm, Sedangkan Untuk pressure suction sebesar 4 bar dan temperaturnya $30^{\circ} \mathrm{C}$. Kemudian untuk pressure discharge pada panel yang berbeda yakni memakai kondisi batas pressure outlet dan Gauge pressure sebesar 1 bar pada temperatur $30^{\circ} \mathrm{C}$. Solusi yang digunakan dalam simulasi ini adalah second order dengan kriteria konvergen sebesar $10^{-5}$ pada kondisi transient. Karena transient, maka menggunakan time step 600 kali dengan number of time step 600 , time step size 0,1 detik. Maks iterations/ time step 20.

c. Pengambilan data hasil pengujian

Tahap ini adalah proses menampilkan hasil serta analisa terhadap hasil yang diperoleh. Adapun data yang akan diambil antara lain kontur pressure, velocity outlet nozzel.

\section{HASIL DAN PEMBAHASAN}

Fokus dari penelitian ini adalah mengetahui diameter exit nozzle yang dapat memberikan performansi paling optimal. Data-data yang ditampilkan berupa kontur pressure, velocity, velocity outlet nozzel dan entaiment rasio

\section{Pengaruh diameter exit nozzel terhadap tekanan statis di suction area}

Setelah dilakukan simulasi menggunakan software Ansys dengan 
tekanan masuk nosel konstan sebesar $400 \mathrm{kPa}$ (4 bar) dan variasi diameter exit nozzel 5, 6 dan 7 $\mathrm{mm}$ maka didapatkan data-data tekanan fluida pada motive area, exit nozzel area dan suction area terlihat pada gambar 4 berikut ini.

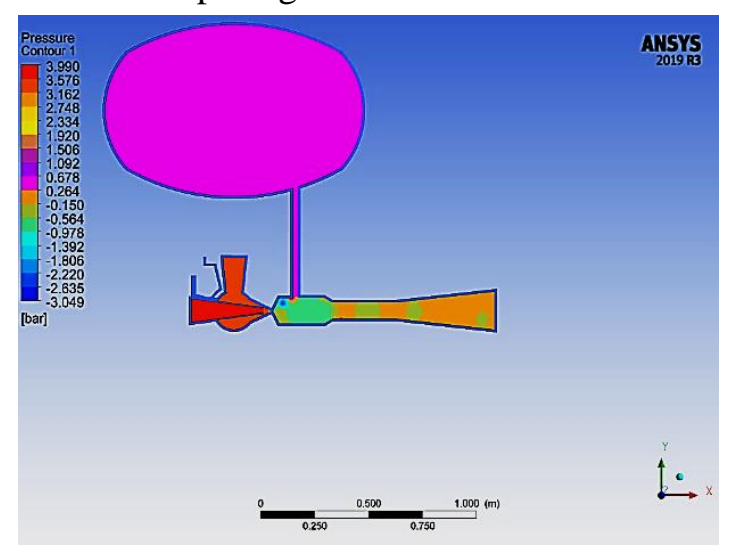

(a)

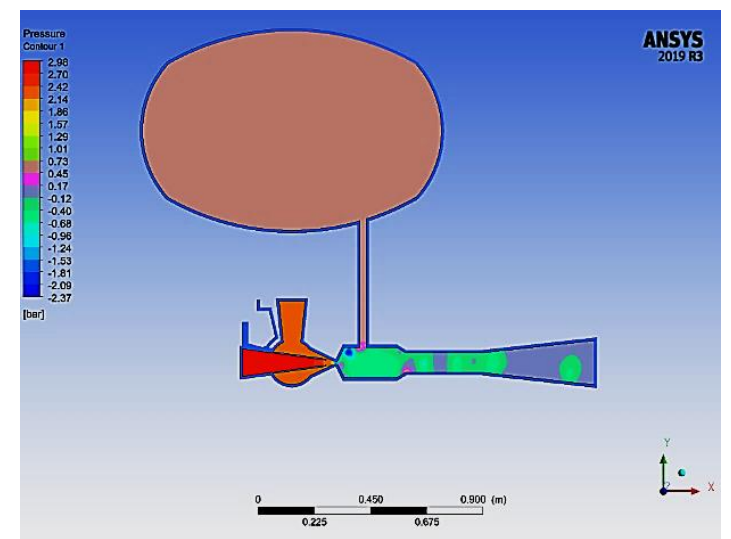

(b)

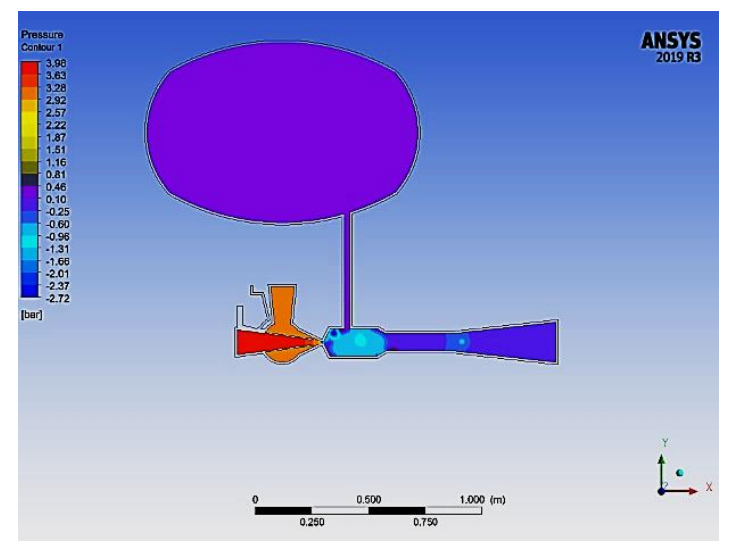

(c)

Gambar 4. Tekanan exit nosel pada diameter Nozzle (a) $5 \mathrm{~mm}$, (b) $6 \mathrm{~mm}$, (c) $7 \mathrm{~mm}$

Untuk melihat perubahan tekanan fluida yang terjadi pada variasi diameter exit nozzel terhadap tekanan di suction area ditunjukkan pada tabel 1 berikut:

\section{Tabel 1. Kontur pressure}

\begin{tabular}{|c|c|c|c|}
\hline \multirow[b]{2}{*}{$\begin{array}{l}\emptyset \text { exit } \\
\text { nozzel }\end{array}$} & \multicolumn{3}{|c|}{ Pressure (bar) } \\
\hline & $\begin{array}{l}\text { Motive } \\
\text { area }\end{array}$ & $\begin{array}{l}\text { Exit } \\
\text { nozzel } \\
\text { area }\end{array}$ & $\begin{array}{l}\text { Suction } \\
\text { area }\end{array}$ \\
\hline $5 \mathrm{~mm}$ & 4 & 0,264 & 0,15 \\
\hline $6 \mathrm{~mm}$ & 4 & 2,14 & 0,45 \\
\hline $7 \mathrm{~mm}$ & 4 & 2,92 & 0,81 \\
\hline
\end{tabular}

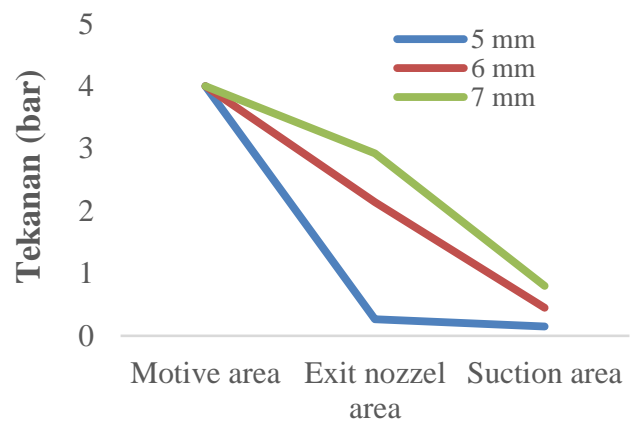

Diameter exit nozzel (mm)

\section{Gambar 5. Variasi Diameter exit nozzle terhadap tekanan statis fluida}

Proses pengujian distribusi tekanan statik fluida pada exit nozzel dilakukan untuk mengetahui besarnya tekanan aliran yang terjadi pada suction area. Tekanan statis fluida diukur pada posisi motive area, bagian luar exit nozzel dan bagian luar suction area. Nilai tekanan tertinggi suction area adalah 0,8 bar pada ukuran diameter exit nozzel $7 \mathrm{~mm}$. Peningkatan tekanan statis fluida di bagian luar suction area seiring dengan perbesaran ukuran diameter exit nozzel yang ditunjukkan pada gambar 5. Hal ini dapat terjadi karena adanya pengaruh perubahan luas penampang venturi, dimana menurut persamaan Bernoulli dikatakan bahwa makin luas sebuah penampang venturi maka makin besar tekanannya (Munson dkk,2004)

\section{Pengaruh diameter exit nozzel terhadap velocity di suction area}

Setelah dilakukan simulasi dengan menggunakan software Ansys dengan tekanan masuk nosel konstan $400 \mathrm{kPa}$ (4 bar) dan variasi diameter exit nozzel 5, 6 dan 7 $\mathrm{mm}$ maka didapatkan data-data kecepatan fluida pada motive area, exit nozzel area dan 
suction area terlihat pada gambar 6 berikut ini.

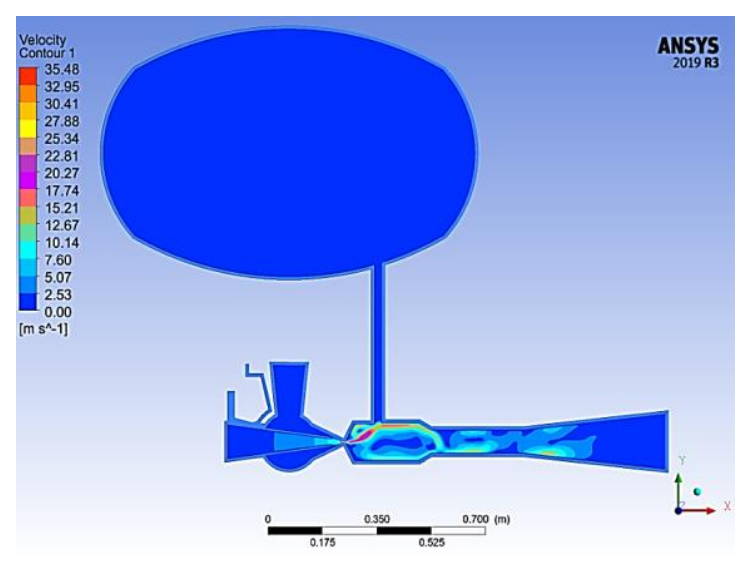

(a)

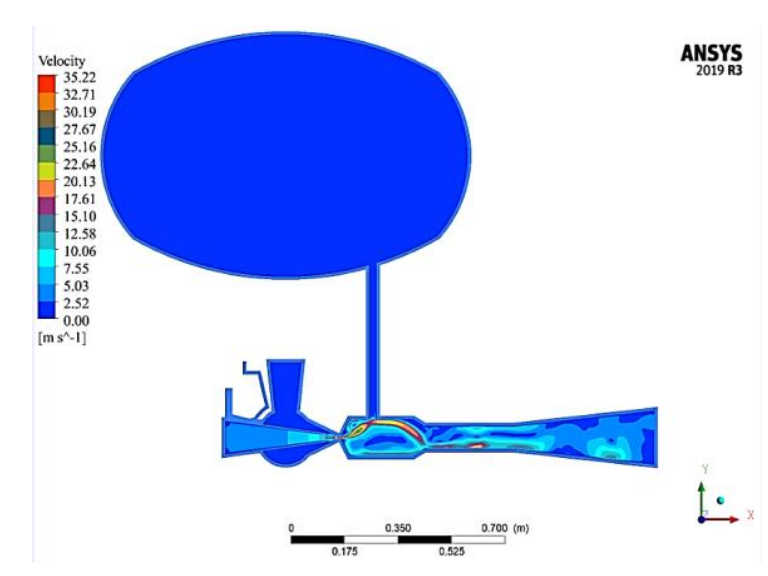

(b)

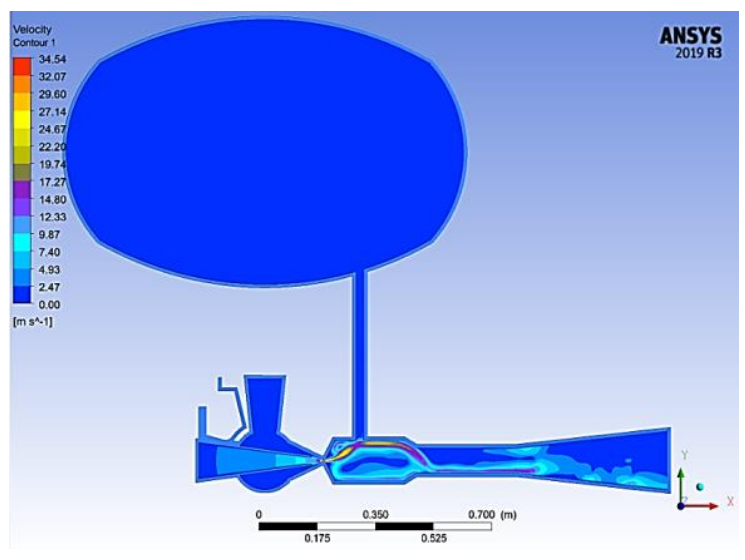

(c)

Gambar 6. Kecepatan fluida exit nosel pada diameter Nozzle (a) $5 \mathrm{~mm}$, (b) $6 \mathrm{~mm}$, (c) 7 mm
Untuk melihat perubahan kecepatan fluida yang terjadi pada variasi diameter exit nozzel terhadap kecepatan fluida di section area ditunjukkan pada tabel 2 berikut:

Tabel 2. Kontur velocity

\begin{tabular}{|c|c|c|c|}
\hline \multirow[b]{2}{*}{$\begin{array}{l}\varnothing \text { exit } \\
\text { nozzel }\end{array}$} & \multicolumn{3}{|c|}{ Velocity $(\mathrm{m} / \mathrm{s})$} \\
\hline & $\begin{array}{l}\text { Motive } \\
\text { area }\end{array}$ & $\begin{array}{l}\text { Exit } \\
\text { nozzel } \\
\text { area }\end{array}$ & $\begin{array}{l}\text { Suction } \\
\text { area }\end{array}$ \\
\hline $5 \mathrm{~mm}$ & 8,4 & 31,81 & 5,07 \\
\hline $6 \mathrm{~mm}$ & 8,4 & 30,191 & 5,032 \\
\hline $7 \mathrm{~mm}$ & 8,4 & 29,08 & 4,93 \\
\hline
\end{tabular}

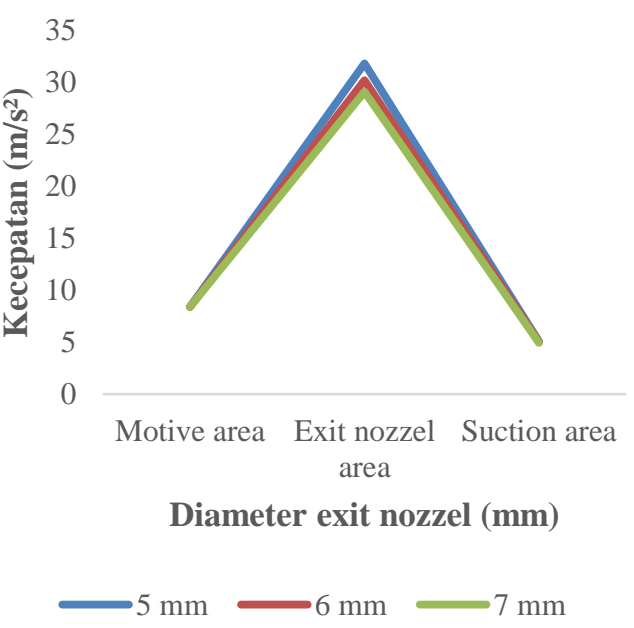

Gambar 7. Variasi Diameter exit nozzle terhadap kecepatan fluida di suction area

Pada gambar 7 di atas, terlihat kontur kecepatan dapat dikatakan meningkat seiring dengan pengecilan ukuran diameter. Semakin kecil area exit nozzel maka kecepatan fluida yang melewatinya akan semakin besar, hal tersebut juga berpengaruh pada kecepatan hisap suction area untuk memvakumkan evaporator. Kecepatan fluida terbesar adalah $31,81 \mathrm{~m} / \mathrm{s}$ terjadi pada diameter exit nozzel 5 $\mathrm{mm}$ dan kecepatan di suction area yang terjadi $5,07 \mathrm{~m} / \mathrm{s}$.

Kondisi dinamika fluida yang terjadi pada area exit nozzel karena efek venturi. Kondisi ini terjadi ketika aliran fluida diberikan tekanan dan temperatur kemudian melewati ke dalam celah yang sempit (seperti 
throat dari convergent-divergent nozzle atau katup di sebuah pipa) sehingga tekanan dari fluida berkurang dan kecepatannya bertambah (Frank, 1988).

\section{PENUTUP}

\section{Kesimpulan}

Berdasarkan analisa yang telah dibahas mengenai pengaruh variasi diameter exit nozzle (5,6 dan $7 \mathrm{~mm}$ ) terhadap performa water ejector dan karakteristik aliran yang melewatinya maka

a. Bila dilihat dari tekanan dipermukaan suction area terbesar adalah 0,81 bar hal tersebut bisa terjadi pada variasi ukuran diameter exit nozzel $7 \mathrm{~mm}$. Tekanan yang terjadi di suction area pada variasi diameter exit nozzel 5, 6 dan $7 \mathrm{~mm}$ masing-masing sebesar 0,$15 ; 0,45$ dan 0,81 bar. Jika dilihat perubahan tekanan yang terjadi sangat signifikan untuk mempercepat vakum evaporator.

b. Bila dilihat dari kecepatan di suction area terbesar adalah $5,07 \mathrm{~m} / \mathrm{s}$ hal tersebut bisa terjadi pada ukuran diameter exit nozzel 5 $\mathrm{mm}$. Kecepatan yang terjadi di suction area pada variasi diameter exit nozzel 5, 6 dan 7 $\mathrm{mm}$ masing-masing sebesar 5,07; 5,03 dan $4,93 \mathrm{~m} / \mathrm{s}$. Jika dilihat perubahan kecepatan yang terjadi kurang signifikan sehingga tidak begitu perpengaruh pada performa ejektor.

Dari data yang diperoleh pada peneltian ini maka dipilih diameter exit nozzel yang optimum adalah $7 \mathrm{~mm}$ karena bisa menghasilkan tekanan di suction area sebesar 0,81 bar.

\section{DAFTAR PUSTAKA}

Zhu, Yinhai, Jiang, Peixue. (2013). Experimental and Numerical Investigation of the Effect of Shock Wave Characteristic on the Ejector Performance. International Journal of Refrigerant. 40, 31- 42,.

Indah $\mathrm{R}, \mathrm{N}$ dan Syamsuri dan Rianata $\mathrm{P}, \mathrm{R}$. (2017). Simulasi Numerik Aliran Melewati Nozzle Pada Ejector Converging-Diverging dengan Variasi Diameter Exit Nozzle. Surabaya, Institut Teknologi Adhi Tama. REM Jurnal2.

Susanto, Muhammad Subri dan Muh.Amin. (2020). Pengaruh Variasi Bukaan Katup
Bypass Primary Flow Dan Diameter Throat Nozzle Terhadap Entrainment Ratio Ejector. Seminar Nasional Teknologi Industri Hijau 3, 109-119.

James R. Lines. (1997). Understanding Ejector systems necessary to troubleshoot vacuum distillation. Oil and gas journal

Rizgar B, Well and Ibrahim J, and Molan,M. 2015. Effect of Nozzle Diameter on Steam Ejector Performance.

Kurdistan, Iraq. University of Salahaddin.

Iing M, Abdurahman, Haris R., (2019), Studi Kinerja Fresh Water Generator Di Kapal AHTS PETEKA 5401, Jurnal Sains 